\title{
OPINIÃO
}

\section{Estabilidade com Crescimento Econômico: uma proposta de ajuste no modelo macroeconômico}

\author{
Helder Ferreira de Mendonça ${ }^{30}$ \\ José Luis Oreiro ${ }^{31}$ \\ Marcelo Luiz Curado ${ }^{32}$
}

A política monetária conduzida pelo Banco Central do Brasil (BCB) nos últimos meses começa a demonstrar seus efeitos. Todos os índices de preços - tanto no atacado como no varejo - apontam para uma redução da inflação. Merecem destaque o comportamento do IPCA - alta de 0,25\% - e a deflação de 0,34\% do IGPM no mês de julho. Ao mesmo tempo, os principais indicadores econômicos apontam para uma redução no crescimento do PIB. A revisão da expectativa de crescimento do produto para 2005 do IPEA de $3,5 \%$ para $2,9 \%$ é sintomática deste cenário mais pessimista sobre as possibilidades de crescimento da economia neste ano.

A redução das expectativas de crescimento é justificada, em especial, pela condução da política monetária. A fixação em 19,75\% a.a. para a taxa de juros Selic deve promover uma redução dos gastos com consumo e investimento. Como os efeitos da variação na política monetária sobre os preços levam entre seis e nove meses para surtirem efeito, é de se esperar que boa parte da retração do consumo e do investimento ocorra apenas no segundo semestre.

Assiste-se também, nos últimos meses, uma perigosa valorização do Real que pode comprometer já este ano o resultado do superávit em Transações Correntes. Não custa nada lembrar que o bom resultado de crescimento do PIB em 2004 foi, em grande medida, fruto do desempenho histórico do setor exportador, resultante do tripé: expansão da economia mundial, elevação dos preços das commodities e câmbio favorável às exportações.

Esta valorização da moeda é o resultado basicamente de dois fenômenos: 1. dos efeitos da taxa de juros sobre a conta de capital num regime de câmbio flutuante no qual o BCB tem primado por não intervir e 2. do contexto internacional de desvalorização do dólar.

\footnotetext{
30 Professor do Departamento de Economia da UFF e Pesquisador do CNPq. Endereço Eletrônico: helderfm@,hotmail.com.

31 Professor do Departamento de Economia da UFPR e Pesquisador do CNPq. Endereço eletrônico: joreiro@,ufpr.br. Web-site: www.joseluisoreiro.ecn.br.

32 Professor do Departamento de Economia da UFPR. Endereço eletrônico: mcurado@ufpr.br.
} 
Desta forma, a política monetária tem contribuído de forma não desprezível para a geração de um taxa de câmbio artificialmente valorizada.

Finalmente, juros elevados ampliam o déficit operacional do governo, o que - dado o limite alcançado pela carga tributária - amplia a necessidade de geração de superávits primários por meio de cortes nos gastos do governo que, via de regra, têm ocorrido por meio de redução dos investimentos públicos em infra-estrutura.

A bem da verdade, a incapacidade de manter a estabilidade de preços com crescimento do produto tem sido a tônica do regime de metas de inflação desde sua implantação no Brasil em 1999. Desde então, a economia brasileira é caracterizada por um processo de stop and go, num período em que, de uma forma geral, a economia mundial apresentou bons resultados.

Tabela 1. Taxa de Crescimento do Produto (variação \% em relação ao ano anterior)

\begin{tabular}{lcccccc}
\hline & 1999 & 2000 & 2001 & 2002 & 2003 & 2004 \\
\hline Mundo & 3,7 & 4,7 & 2,4 & 3 & 3,9 & 5 \\
Economias Desenvolvidas & 3,5 & 3,9 & 1,2 & 1,6 & 2,1 & 3,6 \\
Economias Emergentes & 4 & 5,9 & 4 & 4,8 & 6,1 & 6,6 \\
Emergentes da Ásia & 6,2 & 6,7 & 5,5 & 6,6 & 7,7 & 7,6 \\
Emergentes da Ásia & 6,2 & 6,7 & 5,5 & 6,6 & 7,7 & 7,6 \\
Brasil & 0,8 & 4,4 & 1,3 & 1,9 & $-0,2$ & 4,9 \\
\hline
\end{tabular}

Fonte: Fundo Monetário Internacional.

Os resultados pífios de crescimento do produto brasileiro são derivados, em grande medida, de equívocos na estruturação do regime de metas de inflação e na forma de condução da política monetária.

No intuito de consolidar uma agenda de debate sobre o tema apresentam-se uma série de sugestões de aperfeiçoamento do sistema. Vale ressaltar, para não incorrermos no imperdoável equívoco de não dar crédito há quem merece, que estas propostas vêm sendo analisadas e discutidas em seminários e artigos acadêmicos elaborados por diversos professores de centros de pós-graduação em economia do país. As principais propostas são:

1. Adoção de metas estáveis de inflação. A prática do atual regime monetário de fixação de metas decrescentes de inflação, perseguida desde sua implementação, demonstrouse equivocada para a realidade brasileira. O objetivo desse instrumento, do ponto de vista dos formuladores de política, é sinalizar para o mercado o compromisso com a estabilidade de 
preços, garantindo desta forma a credibilidade com relação à sustentação do processo de estabilização. No entanto, parece mais razoável supor que a credibilidade não se encontra no rigor excessivo da meta, mas sim no cumprimento das metas estabelecidas. As evidências internacionais, assim como todo o referencial teórico de metas de inflação, parecem corroborar a idéia de que a credibilidade é ganha com o cumprimento da meta. A fixação de metas muito ambiciosas não tem de fato contribuído para a redução das taxas de inflação. Seu único efeito é induzir o COPOM a promover políticas monetárias austeras, reduzindo as possibilidades de expansão do produto e do emprego no Brasil. A adoção de metas estáveis de inflação elevaria os graus de liberdade do COPOM na determinação da taxa de juros, contribuindo para o crescimento da demanda agregada e do produto;

\section{Definição das metas de inflação a partir do núcleo do IPCA e não do IPCA}

“cheio". Desde a implantação do regime em 1999 no Brasil utiliza-se um índice de inflação "cheio", no caso o IPCA. Em todos os anos, desde a implantação desse regime, os preços administrados têm pressionado o IPCA, ficando substancialmente acima das variações dos chamados "preços livres" (Relatórios do BCB). A receita do regime de metas nesta situação é contraproducente, pois o COPOM se vê obrigado a elevar a taxa de juros para controlar um processo inflacionário que não tem relação com a expansão da demanda agregada, reduzindo o ritmo de crescimento da economia. Outro equívoco ao se utilizar o IPCA cheio é que o sistema de metas fica vulnerável aos choques de oferta externos. Por exemplo, elevações no preço do petróleo que pressionam o IPCA serão combatidas por intermédio de contração de demanda, reduzindo as possibilidades de crescimento. $O$ uso do núcleo de inflação é prática comum em diversos países. São exemplos - Austrália, Bélgica, Canadá, Cingapura, Espanha, EUA, Filipinas, Finlândia, França, Grécia, Holanda, Israel, Japão, Nova Zelândia, Portugal, Reino Unido e Suécia. A meta deve se concentrar no indicador que capture o comportamento das oscilações nos preços sujeitos à dinâmica de mercado. Choques de oferta e preços administrados devem ser expurgados. Desta forma, as elevações na taxa de juros servirão de fato para controlar a inflação de demanda e não para conter pressões inflacionárias derivadas de contratos ou de choques adversos;

\section{Mudança da forma de apuração das expectativas inflacionárias. Essas} expectativas devem refletir a percepção dos agentes que efetivamente dispõe de poder de formação de preços a respeito da evolução futura da taxa de inflação. Dessa forma, o BCB deve levar em conta as expectativas de inflação de um conjunto mais amplo de agentes. Concretamente, o BCB deve apurar as expectativas de inflação de amplos segmentos da 
indústria e do comércio. Para aumentar a confiabilidade das expectativas assim apuradas, o BCB pode ainda consultar os departamentos de pesquisa econômica de renomadas instituições de ensino superior a respeito de suas previsões sobre a inflação futura. Essas informações serviriam de base para o BCB montar as suas próprias expectativas inflacionárias, as quais são fundamentais para informar a decisão de fixação da taxa de juros pelos membros do COPOM.

\section{Definição da meta para inflação no início de cada ano em comum acordo}

entre o BCB e o Tesouro Nacional. Este procedimento representaria uma melhora na qualidade para a definição da meta. Dessa forma, seriam evitadas as recorrentes alterações nas metas anuais e, por conseguinte, aumentaria a transparência do esforço do governo em assegurar o controle da inflação atenuando o risco sobre a sustentabilidade da dívida pública.

Este conjunto de medidas permitiria uma redução nas taxas de juros nominal e real, ampliando as possibilidades de crescimento do produto. Ademais, a redução da taxa de juros abriria um conjunto de possibilidades no plano fiscal. A redução do comprometimento com o pagamento de juros da dívida e a sustentação do crescimento permitiriam uma diminuição da relação dívida/ PIB. Logo, haveria uma menor necessidade de geração de superávits primários, abrindo possibilidades para expansão dos investimentos públicos em infraestrutura, essenciais para a estratégia de retomada sustentável do crescimento.

A redução da taxa de juros ajudaria a estancar o processo de valorização do Real que ameaça o crescimento deste ano. É bem possível que para que isto se concretize seja necessário que o $\mathrm{BCB}$ realize intervenções no mercado de câmbio, por meio da compra de divisas. Tais medidas são plenamente aceitáveis num regime de flutuação cambial com intervenção (dirty floating) e contribuiriam para: 1. manter uma taxa de câmbio compatível com a geração de superávits comerciais no médio prazo; 2. elevar as reservas internacionais, reduzindo os indicadores de risco país e; 3 elevar a liquidez do sistema econômico, compatível com a redução nas taxas de juros.

Em suma, este conjunto de propostas pretende aperfeiçoar o modelo macroeconômico vigente a partir de alterações no regime de metas de inflação e na forma de condução da política monetária, permitindo que a economia brasileira deixe de ostentar o título inglório e economicamente injustificável de detentora da maior taxa de juros real do mundo. Espera-se também que tais medidas ajudem os formuladores de política econômica a encontrarem o caminho, até agora distante, de manutenção da estabilidade com crescimento econômico.

96 